\title{
Physician Burnout: Achieving Wellness for Providers and Patients
}

\author{
Jonathan A Niconchuk ${ }^{1}$ (D) - Steve Alan Hyman ${ }^{1}$ \\ Published online: 3 July 2020 \\ (C) Springer Science+Business Media, LLC, part of Springer Nature 2020
}

\begin{abstract}
Purpose of Review This review summarizes the history and scope of physician burnout, and explores recent advances in its understanding. With a particular focus on physicians who have completed their training, it also explores the present and future of interventions designed to alleviate the symptoms and sequelae of burnout.

Recent Findings Nearly 50 years since first described, burnout continues to remain a pervasive issue within anesthesia and medicine as a whole. Recent work has continued to outline risk factors and specialty-specific prevalence, and explore individual and institutional interventions to prevent and treat symptoms.

Summary Burnout continues to impact all who work in healthcare, at all levels of training. This review highlights recent advances in our understanding of the scope, causes, and management of burnout. In light of the current COVID-19 pandemic, we hope that the national and international focus on preventing and remediating burnout will continue to expand and strengthen.
\end{abstract}

Keywords Burnout $\cdot$ Physician burnout $\cdot$ Wellness $\cdot$ Job satisfaction $\cdot$ Mental health $\cdot$ COVID-19

\section{Search Strategy}

This review focuses on research performed in the past 5 years, with a particular focus on physicians who have completed their training. All searches were conducted in PubMed and all references, with the exception of the key papers referenced above in the introduction, were published between January 1, 2015, and April 10, 2020. The search for "burnout" yielded 6925 published articles. When narrowed to "physician burnout", the search yielded 2168 articles, 213 of which were classified as review articles. When further constricted to "anesthesiology burnout", 159 papers were identified, all of which were reviewed for this article. Inclusion in this review was determined based on relevance and expert review.

This article is part of the Topical Collection on Patient Safety in Anesthesia

Jonathan A Niconchuk

jon.niconchuk@vumc.org

Steve Alan Hyman

steve.hyman@vumc.org

1 Department of Anesthesiology, Vanderbilt University Medical Center, 1301 Medical Center Drive, Nashville, TN 37232-7614, USA

\section{Introduction}

In the mid-1970s, a psychologist named Hebert Freudenberger, Jr. gave a name to a constellation of symptoms that had existed long before his time. Freudenberger observed increased demands on energy, strength, and resources that led to "failure or exhaustion" of childcare workers [1, 2]. In 1981, Maslach and Jackson introduced specific descriptors and a tool known as the Maslach Burnout Inventory (MBI). A later modification, the Human Services Survey (HSS), was designed specifically for healthcare workers [3]. This opened the door to rapidly expand the body of literature focusing on burnout. The triad of emotional exhaustion, depersonalization, and decreased sense of personal accomplishment—alongside the cynicism and decline in quality of care that followed in its wake - defined burnout, and no occupation seemed immune. In 1986, Rafferty et al. used the MBI-HSS in family practitioners, providing validation and precedent for the ongoing use of the MBI-HSS in clinicians [4]. Over the next two decades, physicians within many specialties and at every level of training continued to display concerning symptoms, and the focus on burnout intensified. In 2008, Halbesleben and Rathert showed burnout affected not only providers but patients as well, demonstrating that patients cared for by physicians who reported symptoms of burnout, particularly depersonalization, had lower satisfaction scores and longer recovery times [5]. A recent comprehensive publication by the 
National Academy of Medicine suggests that care provided by burned out providers is less safe and less patient focused [6••].

With both providers and patients at risk due to burnout, work to assess the depth and scale of the problem among physicians accelerated. Unfortunately, the results were jarring. In 2012, Shanafelt et al. published survey results of nearly 8000 US physicians and showed that rates of burnout and dissatisfaction with work-life balance among physicians were significantly higher than adults working in other professions [7]. In the subsequent 4 years, the incidence of burnout increased by $10 \%$, affecting more than half $(54 \%)$ of all physicians surveyed $[8 \bullet$. Additionally, our group showed that within the perioperative arena, physicians in particular were more likely to report burnout compared with other perioperative providers [9].

\section{What Causes Burnout}

Freudenberger and then Maslach both postulated that increased workload and ever-increasing demands on energies and resources led to the hallmark symptoms of burnout: the state of chronic physical and emotional depletion termed emotional exhaustion (EE), the sense of disconnection from colleagues and patients known as depersonalization (DP), and the negative sense of self and one's ability known as personal accomplishment (PA). The proposed causes of burnout may affect one or all of these domains, and the proposed causes have been numerous.

One of the most important and controversial questions is relatively simple: is burnout due to extrinsic or intrinsic factors, or both? Is an individual physician more prone to burnout due to personal circumstance or genetic predisposition? Or do the realities of the profession impose conditions that make imbalance almost inevitable in today's healthcare ecosystem [10 $]$ ? Or perhaps burnout is simply due to more time spent at work? For example, among intensivists, it has been shown that more night shifts, more consecutive working days, and more time since last non-working week all are risk factors for burnout [11]. Ongoing research linking sleep disturbance and deprivation to burnout has provided a biologic underpinning to this correlation between workload and burnout, as nicely summarized by Stewart and Arora in 2019 [12].

Physician workload has also increased due to technology and the rise of the electronic health record (EHR), and increased use of the EHR has been linked repeatedly to increased risk of burnout [13]. For perspective, one group postulated that for each doubling of the length of a clinical note, the risk of burnout increases by $10 \%$ [14]. By simultaneously increasing physician workload and decreasing physicianpatient engagement, technology has provided a double hit of sorts as it relates to burnout risk.
We must also acknowledge the role of gender, as some (but not all) studies have suggested a higher rate of burnout among female physicians. Despite this possible excess rate of burnout, recent data have suggested that patients cared for by female physicians may have better outcomes [15]. While much work remains, recent literature has focused on the patient panel characteristics of female providers and differential gender expectations among patients [16]. Admittedly, the relevance to anesthesiology of this work may be limited, and more research is needed.

\section{Scope of the Problem}

While this review primarily focuses on anesthesiology, it is important to understand just how widespread and pervasive burnout remains within the medical field at large. In the last 5 years, over one paper per day has been published on the topic of physician burnout alone. More than 13 specialties have published review articles addressing burnout within their respective fields, just within the past 5 years. Surgeons have noticed a sharp rise in burnout, as high as $53 \%$, with Dimou et al. calling for increased interventions to go along with the increasing incidence [17]. In a systematic review, Pulcrano and colleagues noted that incidence of burnout varies among surgical subspecialties, with plastic surgery, general surgery, and vascular surgery perhaps being more at risk [18]. Obstetricians, pathologists, oncologists, cardiologists, gastroenterologists, and emergency medicine physicians (among many others) have all published similarly worrying statistics and calls for action [19-24].

Within anesthesia, Sanfilippo and colleagues published a systematic review revealing burnout at all layers and stages of the anesthesia workforce across the world, while also correctly pointing out the variability in alterations of the MBI-HSS and in defining cutoff criteria for the three main elements of emotional exhaustion, depersonalization, and personal accomplishment [25]. The most recent large-scale data for residents and first year graduates in anesthesiology reveal a rate of burnout of $51 \%$ [26•]. Additional recent studies have confirmed that residents in particular do seem prone to a higher rate of burnout, though this risk appears to extend to all physicians under age 50, with the risk decreasing in older physicians [9, 27]. More recent unpublished data from our group corroborate these rates within subspecialty anesthesiologists, particularly chronic pain physicians. The data remain very clear; burnout continues to affect nearly half of all anesthesiologists, critical care physicians, and pain physicians. 


\section{Why It Matters}

With the high prevalence of burnout, it is critical to note that burnout does not only impact individual physicians; it also impacts patients. Over a decade ago, Halbesleben and colleagues linked physicians reporting burnout to patients who had lower satisfaction scores and increased recovery times [5]. In 2010, Shanafelt showed that surgeons who reported symptoms of burnout were also more likely to report a major medical error in the past 3 months [28]. More recently, Panagioti et al. published a meta-analysis confirming much of what we already suspected: burnout is associated with a nearly doubled risk of patient safety incidents, and a more than doubling of the risk of decreased patient satisfaction and poorer quality of care secondary to poor professionalism [29]. Tawfik and colleagues also presented data confirming that increased major medical errors were independently associated with physicians showing symptoms of burnout or fatigue [30].

While it is clear that physician burnout impacts patients, we must not overlook that impact on the physicians themselves. Burnout has been linked to lower mental and physical health, and decreased job performance. This effect is unfortunately not transient; Raimo and colleagues recently showed that stress and emotional distress that occur during residency increase the rate of burnout 10 years later, after a provider is well into their practicing years [31]. Burnout is involved in a dangerous downward spiral in that burnout contributes to increased medical errors which in turn leads to worsening burnout [32]. The directionality of this link remains debated, though the data are clear that a strong correlation exists between burnout and medical errors. It was long believed that burnout also could lead to increased risk of substance abuse, though more recent data from our group have demonstrated that this link may not be as strong as once believed [10•].

With the SARS-CoV-2 pandemic sweeping the globe, the risk of worsening burnout among physicians and all allied health professionals is profound. This virus presents a perfect storm for worsening burnout with increased work in the midst of inadequate resources, compounded for many by decreased pay and other financial and personal stressors. In the general population, prescriptions for anti-anxiety medications increased by $34 \%$ from mid-February to mid-March, despite falling $12 \%$ between 2015 and 2019 [33]. It is reasonable to assume that physicians are at an even higher risk of anxiety than the general population, and burnout symptoms become all the more likely as the crisis continues. It is encouraging to see international calls for mental health research during this pandemic [34]. This research must extend to physicians on the frontlines, including anesthesiologists, and fortunately our specialty is already heeding this call. Anesthesiologists have been on the front lines of the clinical response and should therefore also be on the front line of the policy response. Sasangohar and colleagues have called for enhanced crisis management training, improved communication and transparency regarding availability of supplies, and a streamlining of regulation to allow for more efficient use of human resources such as physicians working across state lines. [35] Importantly, we echo the call for "feasible and practical methods to assess health care workers' fatigue and burnout" including the expanded use of wearable technology and other innovative means of collecting data to drive decision-making.

While the links between burnout and physician mental health have been the primary focus of investigation, burnout may also have physical sequelae. The association between chronic stress and increased inflammation and decreased immune function has long been understood [36]. However, any formal study of chronic physician burnout and physical sequelae has been lacking. Understanding the potential biologic and metabolic consequences of chronic burnout and stress will be vital to our future understanding of burnout as well as how to best target future interventions.

\section{What Makes It Better}

As the understanding of both the scale and the causes of burnout has continued to take shape, just as much work has been done attempting to find mitigation and treatment strategies. Just as the causes of burnout can be both internal and external, the interventions for burnout can be targeted at either the individual or institutional level. Fortunately, there has been some good news. In 2016, West and colleagues reported a meta-analysis that included data from over 3500 physicians that showed a decrease in overall burnout from 54 to $44 \%$ due to both individual and institutional interventions [37•]. In recent years, this work has continued and has been targeted more to specific subpopulations. Some groups have focused more on institutional interventions, with Shanafelt and his group proposing nine data-driven organizational strategies to reduce burnout, beginning with acknowledging the problem and having leadership that is invested in cultivating a culture and community which promotes healthy work-life integration [38] (Table 1). Shapiro et al. proposed focusing on a tiered institutional approach based on Maslow's hierarchy of needs to address burnout, starting with meeting physician's basic physical and mental health needs [39].

With the current level of interest in burnout and wellness, one might envision (albeit incorrectly) a robust literature evaluating interventions. In the meta-analysis by West, only 50 60 papers met inclusion criteria, and these were generally of low quality and lacked long-term follow-up [37•]. Interventions, mostly involving stress management and individual behavior training, caused a modest reduction in emotional exhaustion and burnout risk. Recent studies have also proposed interventions such as exercise [40], self-care [41], better feedback and mentorship [42], peer-support programs 
Table 1 Layers of physician burnout - a multifactorial problem

\begin{tabular}{|c|c|c|c|c|}
\hline & Job demands & "Production pressure" & Workplace culture & Work/life balance \\
\hline Individual level & $\begin{array}{l}\text { Specialty, location } \\
\text { of practice, call } \\
\text { schedule }\end{array}$ & $\begin{array}{l}\text { Personal efficiency, } \\
\text { setting limits and ability } \\
\text { to "say no" }\end{array}$ & $\begin{array}{l}\text { Personal and traits, ability to self-shape } \\
\text { career }\end{array}$ & $\begin{array}{l}\text { Personal characteristics (spouse/partner, } \\
\text { children) }\end{array}$ \\
\hline $\begin{array}{l}\text { Work cluster } \\
\text { level }\end{array}$ & $\begin{array}{l}\text { Team structure, } \\
\text { presence of allied } \\
\text { health } \\
\text { professionals }\end{array}$ & $\begin{array}{l}\text { Availability and } \\
\text { experience of support } \\
\text { staff }\end{array}$ & $\begin{array}{l}\text { Behavior of work unit leadership, } \\
\text { fairness and equity of workload, } \\
\text { matching interest and talent to work }\end{array}$ & $\begin{array}{l}\text { Assignments and scheduling, } \\
\text { cross-coverage and availability of } \\
\text { help when needed }\end{array}$ \\
\hline $\begin{array}{l}\text { Organization } \\
\text { level }\end{array}$ & $\begin{array}{l}\text { Compensation } \\
\text { structure, } \\
\text { productivity } \\
\text { targets }\end{array}$ & $\begin{array}{l}\text { Care integration across } \\
\text { departments, use of } \\
\text { EHR }\end{array}$ & $\begin{array}{l}\text { Behavior of senior leaders, } \\
\text { opportunities for professional } \\
\text { development }\end{array}$ & $\begin{array}{l}\text { Vacation policies, sick leave, } \\
\text { availability of part time schedule }\end{array}$ \\
\hline $\begin{array}{l}\text { National/policy } \\
\text { level }\end{array}$ & $\begin{array}{l}\text { Reimbursement } \\
\text { structure } \\
\text { (Medicare, } \\
\text { Medicaid, etc.) }\end{array}$ & $\begin{array}{l}\text { Insurance regulations, care } \\
\text { integration across } \\
\text { multiple facilities/states }\end{array}$ & $\begin{array}{l}\text { Interaction with medical/specialty } \\
\text { societies, evolving supervision } \\
\text { requirements for physicians }\end{array}$ & $\begin{array}{l}\text { Maintenance of certification } \\
\text { requirements, regulations and } \\
\text { documentation that occupy } \\
\text { non-clinical time }\end{array}$ \\
\hline
\end{tabular}

Adapted from Shanafelt [39]

[43], and mindfulness [44]. At this point, no specific interventions could be recommended, but the West analysis suggests that doing something is better than doing nothing. Although more high-quality data are needed to prove that any individual intervention is superior, it is clear that a multifactorial problem will require a multifactorial solution.

A broad literature focus remains on "increasing resilience" among physicians. This approach, without a simultaneous focus on institutional problems, can have the unintended consequence of placing blame on individual providers for a perceived shortcoming when resilience is not readily achieved. This could lead to a decrease in reporting or seeking help. In fact, some have advocated for taking personality traits that may lead to future burnout into account in the resident selection process [45]. We advocate for an approach which balances individual and institutional approaches, while fostering an environment that encourages reporting and open discussion.

\section{Conclusion}

In May of 2019, the 11th edition of the International Classification of Disease (ICD-11) defined burnout as "a syndrome conceptualized as resulting from chronic workplace stress that has not been successfully managed. It is characterized by three dimensions: feelings of energy depletion or exhaustion, increased mental distance from one's job, or feelings of negativism or cynicism related to one's job, and reduced professional efficacy" [46]. Of note, burnout syndrome was not included as a medical diagnosis, but rather an occupational hazard. With roughly half of all physicians experiencing burnout and over a paper on physician burnout per day being published, in
October 2019, the National Academy of Sciences released a groundbreaking comprehensive report outlining the cost and consequences of clinician burnout [6・•] (Table 2). These events are both important steps in placing burnout in the foreground of the national and international research community. We also appreciate the calls to expand burnout research to low- and middle-income countries, as it is becoming clear that burnout is not confined to any region or income level across the globe [47].

However, much work remains to better define and characterize burnout within the literature. While the MBI-HSS remains the gold standard, it almost always

Table 2 Costs and consequences associated with provider burnout

\begin{tabular}{|c|c|c|}
\hline Personnel issues & Quality of care issues & Costs \\
\hline Decreased job effort & $\begin{array}{l}\text { Decreased patient } \\
\text { satisfaction }\end{array}$ & $\begin{array}{l}\text { Estimated annual } \\
\text { financial cost- } \\
\text { \$4B }\end{array}$ \\
\hline Increased absenteeism & $\begin{array}{l}\text { Increased surgical site } \\
\text { and other infections }\end{array}$ & $\begin{array}{l}\text { Societal cost- } \\
\text { unknown }\end{array}$ \\
\hline "Presenteeism" & $\begin{array}{l}\text { Increased number of } \\
\text { medical errors }\end{array}$ & \\
\hline $\begin{array}{l}\text { Personnel taking other } \\
\text { positions elsewhere }\end{array}$ & $\begin{array}{l}\text { Increased number of } \\
\text { patient safety } \\
\text { incidents }\end{array}$ & \\
\hline $\begin{array}{l}\text { Leaving the profession } \\
\text { altogether }\end{array}$ & $\begin{array}{l}\text { Omission of necessary } \\
\text { care }\end{array}$ & \\
\hline \multirow[t]{2}{*}{$\begin{array}{l}\text { Reduced revenue during } \\
\text { personnel transition }\end{array}$} & $\begin{array}{l}\text { Increased risk of } \\
\text { litigation }\end{array}$ & \\
\hline & $\begin{array}{l}\text { Increased patient } \\
\text { mortality }\end{array}$ & \\
\hline
\end{tabular}

Adapted from National Academies of Sciences, Engineering, and Medicine 2019 [6••] 
altered in various ways for individual studies. These variations likely do not impact the validity of individual studies, yet it does make comparative evaluation challenging. In a similar manner, variations in cutoff points for measuring symptomatology can also make comparative evaluation difficult. Finally, a long-standing concern in the burnout literature remains that the reliance on surveys and self-reporting may over- or underrepresent the true incidence due to response bias. These challenges were summarized by Ong and colleagues in a recent letter to the editor of Anesthesiology [48].

We the authors have been personally affected by burnout and have talked to many colleagues experiencing burnout. We have felt that feeling of dread while driving to work, the loss of motivation to achieve personal or professional goals, or the feeling of isolation from coworkers, friends, and even family. For those experiencing burnout, it often feels exceptionally lonely. As 30 years of study have shown, those experiencing burnout are anything but alone. Burnout continues to impact half of all physicians, and we look forward to continuing to expand our knowledge of how to best identify and ameliorate these symptoms that have become all too familiar.

\section{References}

Papers of particular interest, published recently, have been highlighted as:

- Of importance

•• Of major importance

1. Freudenberger HJ. The staff burn-out syndrome in alternative institutions. Psychotherapy. 1975;12(1):73-82.

2. Freudenberger HJ. Burn-out: occupational hazard of the child care worker. Child Care Q. 1977;6:90-9.

3. Maslach C, Jackson SE. The measurement of experienced burnout. J Organ Behav. 1981;2(2):99-113.

4. Rafferty JP, Lemkau JP, Purdy RR, Rudisill JR. Validity of the Maslach Burnout Inventory for family practice physicians. J Clin Psychol. 1986;42(3):488-92.

5. Halbesleben JR, Rathert C. Linking physician burnout and patient outcomes: exploring the dyadic relationship between physicians and patients. Health Care Manag Rev. 2008;33(1):29-39.

6.• Medicine NAo, National Academies of Sciences E, Medicine. Taking action against clinician burnout: a systems approach to professional well-being. Washington, DC: The National Academies Press; 2019. 334 p. The most comprehensive academic publication related to physician burnout to date; this publication from the NAS globally looks at problems that affect physicians in general and the work they produce in the process of patient care.

7. Shanafelt TD, Boone S, Tan L, Dyrbye LN, Sotile W, Satele D, et al. Burnout and satisfaction with work-life balance among US physicians relative to the general US population. Arch Intern Med. 2012;172(18):1377-85.
8. Shanafelt TD, Hasan O, Dyrbye LN, Sinsky C, Satele D, Sloan J, et al. Changes in burnout and satisfaction with work-life balance in physicians and the general US working population between 2011 and 2014. Mayo Clin Proc. 2015;90(12):1600-13. This article built on the landmark study cited above which compared US physicians with the general population and showed a higher incidence of burnout. This paper confirmed that the increased incidence was both persistent over time and pervasive across specialties, and served as a clarion call to increase attention and energy on the problem of physician burnout.

9. Hyman SA, Michaels DR, Berry JM, Schildcrout JS, Mercaldo ND, Weinger MB. Risk of burnout in perioperative clinicians: a survey study and literature review. Anesthesiology. 2011;114(1):194-204.

10. Hyman SA, Shotwell MS, Michaels DR, Han X, Card EB, Morse JL, et al. A survey evaluating burnout, health status, depression, reported alcohol and substance use, and social support of anesthesiologists. Anesth Analg. 2017;125(6):2009-18. For burnout within anesthesiologists specifically, this article bears mention as the first published work to look at anesthesiologists in general as a specific group.

11. Pastores SM, Kvetan V, Coopersmith CM, Farmer JC, Sessler C, Christman JW, et al. Workforce, workload, and burnout among intensivists and advanced practice providers: a narrative review. Crit Care Med. 2019;47(4):550-7.

12. Stewart NH, Arora VM. The impact of sleep and circadian disorders on physician burnout. Chest. 2019;156(5):1022-30.

13. Ehrenfeld JM, Wanderer JP. Technology as friend or foe? Do electronic health records increase burnout? Curr Opin Anaesthesiol. 2018;31(3):357-60.

14. Lilly CM, Cucchi E, Marshall N, Katz A. Battling intensivist burnout: a role for workload management. Chest. 2019;156(5):1001-7.

15. Tsugawa Y, Jena AB, Figueroa JF, Orav EJ, Blumenthal DM, Jha AK. Comparison of hospital mortality and readmission rates for Medicare patients treated by male vs female physicians. JAMA Intern Med. 2017;177(2):206-13.

16. Linzer M, Harwood E. Gendered expectations: do they contribute to high burnout among female physicians? J Gen Intern Med. 2018;33(6):963-5.

17. Dimou FM, Eckelbarger D, Riall TS. Surgeon burnout: a systematic review. J Am Coll Surg. 2016;222(6):1230-9.

18. Pulcrano M, Evans SR, Sosin M. Quality of life and burnout rates across surgical specialties: a systematic review. JAMA Surg. 2016;151(10):970-8.

19. Smith RP. Burnout in obstetricians and gynecologists. Obstet Gynecol Clin N Am. 2017;44(2):297-310.

20. Hernandez JS, Wu RI. Burnout in pathology: suggestions for individual and systemwide solutions. J Am Soc Cytopathol. 2018;7(3): $166-8$.

21. Murali K, Banerjee S. Burnout in oncologists is a serious issue: what can we do about it? Cancer Treat Rev. 2018;68:55-61.

22. Panagioti M, Geraghty K, Johnson J. How to prevent burnout in cardiologists? A review of the current evidence, gaps, and future directions. Trends Cardiovasc Med. 2018;28(1):1-7.

23. Barnes EL, Ketwaroo GA, Shields HM. Scope of burnout among young gastroenterologists and practical solutions from gastroenterology and other disciplines. Dig Dis Sci. 2019;64(2):302-6.

24. Stehman CR, Testo Z, Gershaw RS, Kellogg AR. Burnout, drop out, suicide: physician loss in emergency medicine. Part I West J Emerg Med. 2019;20(3):485-94.

25. Sanfilippo F, Noto A, Foresta G, Santonocito C, Palumbo GJ, Arcadipane A, et al. Incidence and factors associated with burnout in anesthesiology: a systematic review. Biomed Res Int. 2017;2017:8648925.

26. Sun H, Warner DO, Macario A, Zhou Y, Culley DJ, Keegan MT. Repeated cross-sectional surveys of burnout, distress, and depression among anesthesiology residents and first-year graduates. 
Anesthesiology. 2019;131(3):668-77. The most comprehensive work that looks at burnout among anesthesia residents published to date, which will likely serve as baseline data for multiple future studies.

27. Shah A, Wyatt M, Gourneau B, Shih G, De Ruyter M. Emotional exhaustion among anesthesia providers at a tertiary care center assessed using the MBI burnout survey. Psychol Health Med. 2019;24(5):620-4.

28. Shanafelt TD, Balch CM, Bechamps G, Russell T, Dyrbye L, Satele $\mathrm{D}$, et al. Burnout and medical errors among American surgeons. Ann Surg. 2010;251(6):995-1000.

29. Panagioti M, Geraghty K, Johnson J, Zhou A, Panagopoulou E, Chew-Graham C, et al. Association between physician burnout and patient safety, professionalism, and patient satisfaction: a systematic review and meta-analysis. JAMA Intern Med. 2018;178(10):1317-30.

30. Tawfik DS, Profit J, Morgenthaler TI, Satele DV, Sinsky CA, Dyrbye LN, et al. Physician burnout, well-being, and work unit safety grades in relationship to reported medical errors. Mayo Clin Proc. 2018;93(11):1571-80.

31. Raimo J, LaVine S, Spielmann K, Akerman M, Friedman KA, Katona $\mathrm{K}$, et al. The correlation of stress in residency with future stress and burnout: a 10-year prospective cohort study. J Grad Med Educ. 2018;10(5):524-31.

32. Moss M, Good VS, Gozal D, Kleinpell R, Sessler CN. An official critical care societies collaborative statement: burnout syndrome in critical care healthcare professionals: a call for action. Crit Care Med. 2016;44(7):1414-21.

33. https://www.express-scripts.com/corporate/americas-state-ofmind-report. Accessed 4/17/2020.

34. Holmes EA, O'Connor RC, Perry VH, Tracey I, Wessely S, Arseneault L, et al. Multidisciplinary research priorities for the COVID-19 pandemic: a call for action for mental health science. Lancet Psychiatry.

35. Sasangohar F, Jones SL, Masud FN, Vahidy FS, Kash BA. Provider burnout and fatigue during the COVID-19 pandemic: lessons learned from a high-volume intensive care unit. Anesth Analg. 2020. Epub ahead of print;131:106-11.

36. Dhabhar FS. Effects of stress on immune function: the good, the bad, and the beautiful. Immunol Res. 2014;58(2-3):193-210.
37. West CP, Dyrbye LN, Erwin PJ, Shanafelt TD. Interventions to prevent and reduce physician burnout: a systematic review and meta-analysis. Lancet. 2016;388(10057):2272-81. An important paper in the sense that it transitioned from examining prevalence at scale to investigating interventions at scale. This paper reviewed all available evidence on strategies to treat burnout, and set the stage for ongoing work in treatment and prevention of burnout.

38. Shanafelt TD, Noseworthy JH. Executive leadership and physician well-being: nine organizational strategies to promote engagement and reduce burnout. Mayo Clin Proc. 2017;92(1):129-46.

39. Shapiro DE, Duquette C, Abbott LM, Babineau T, Pearl A, Haidet P. Beyond burnout: a physician wellness hierarchy designed to prioritize interventions at the systems level. Am J Med. 2019;132(5):556-63.

40. Parry DA, Oeppen RS, Amin MSA, Brennan PA. Could exercise improve mental health and cognitive skills for surgeons and other healthcare professionals? Br J Oral Maxillofac Surg. 2018;56(5): 367-70.

41. Kuhn CM, Flanagan EM. Self-care as a professional imperative: physician burnout, depression, and suicide. Can J Anaesth. 2017;64(2):158-68.

42. Gordon EK, Baranov DY, Fleisher LA. The role of feedback in ameliorating burnout. Curr Opin Anaesthesiol. 2018;31(3):361-5.

43. Vinson AE, Randel G. Peer support in anesthesia: turning war stories into wellness. Curr Opin Anaesthesiol. 2018;31(3):382-7.

44. Answine JF, Lu AC, Levy TSM. Burnout, wellness, and resilience in anesthesiology. Int Anesthesiol Clin. 2019;57(3):138-45.

45. van der Wal RAB, Wallage J, Bucx MJL. Occupational stress, burnout and personality in anesthesiologists. Curr Opin Anaesthesiol. 2018;31(3):351-6.

46. The L. ICD-11. Lancet. 2019;393(10188):2275.

47. Milenovic MS, Matejic BR, Simic DM, Luedi MM. Burnout in anesthesiology providers: shedding light on a global problem. Anesth Analg. 2020;130(2):307-9.

48. Ong J, Lim WY, Ong S. Anesthesiologist burnout, distress, and depression: comment. Anesthesiology. 2020;132:1599-601.

Publisher's Note Springer Nature remains neutral with regard to jurisdictional claims in published maps and institutional affiliations. 